\title{
Megaeventos esportivos e Educação Física: alerta de tsunami
}

Fernando Mascarenhas*

\begin{abstract}
Resumo: Este texto analisa as implicações dos megaeventos esportivos em diferentes âmbitos da realidade nacional. Neste ínterim, a partir da relacional Estado, organização esportiva e mercado, problematiza as relações de hegemonia e estratégias de acumulação inerentes à agenda Rio 2016. Além disso, apresenta uma discussão sobre como a Educação Física e as Ciências do Esporte se inserem neste processo, registrando alguns apontamentos para os seus agentes e instituições acadêmico-científicas.
\end{abstract}

Palavras-chave: Megaeventos esportivos; políticas públicas; educação física.

\section{INTRODUÇÃo}

Antes de tudo, gostaria de agradecer aos editores. $\mathrm{Na}$ área da Educação Física brasileira, todos sabem o quão repercutiu positivamente a Revista Movimento e sua seção Temas Polêmicos. Participar da reativação deste espaço é, portanto, ao mesmo tempo, honraria e desafio. Sou grato pela confiança e espero poder corresponder ao convite, sobretudo, pelo tema proposto para discussão, os megaeventos esportivos, objeto de meus estudos a bem pouco tempo. Um segundo registro diz respeito ao contexto de produção deste texto, derivado de uma síntese originalmente preparada na forma de apresentação oral, cuja socialização se deu em mesa de debate durante o XVII Congresso Brasileiro de Ciências do Esporte e IV Congresso Internacional de Ciências do Esporte, realizado em setembro de 2011, em Porto Alegre.

\footnotetext{
*Professor Doutor da Universidade de Brasília. E-mail: fernandom@unb.br.
} 
Deste modo, a discussão que hora traduzo para a escrita tem como ponto de partida a problemática levantada pelos organizadores daquele evento, recolocada pelos editores deste periódico, a saber: Quais as implicações dos megaeventos esportivos nos diferentes âmbitos da realidade nacional? Como se inserem a Educação Física e as Ciências do Esporte neste processo? Dentre os megaeventos a serem sediados no país, Jogos Mundiais Militares de 2011, a Copa das Confederações de 2013, a Copa do Mundo FIFA de 2014 e a Copa América de 2015, elegi para os fins desta discussão, analisar os Jogos Olímpicos e Paraolímpicos de 2016, considerando que seus efeitos sobre a Educação Física tendem a ser mais significativos.

Sumariando a exposição, anuncio quatro momentos. O primeiro, en passant, além de permitir uma aproximação ao tema dos megaeventos, destina-se a alguns esclarecimentos prévios sobre a relação dos Jogos com a cidade do Rio de Janeiro e o país. O segundo, analítico e mais demorado, aborda o projeto Rio 2016, as políticas aos quais está articulado e os interesses que o perpassam. O terceiro, alerta para os prováveis impactos dos Jogos na escola. Por fim, em caráter conclusivo, chamo atenção para a necessidade de se pautar o tema dos megaeventos na agenda de pesquisas da área da Educação Física e Ciências do Esporte, bem como apresenta alguns apontamentos para os seus agentes e instituições acadêmicocientíficas.

\section{Os JOGOS E O PAís}

Os Jogos Olímpicos e Paraolímpicos de 2016 - ou, simplesmente, os Jogos - serão os Jogos da cidade do Rio de Janeiro ou os Jogos do Brasil? Uma reflexão sobre esta pergunta é fundamental para a discussão que pretendo desenvolver. Óbvio que é a cidade a sede olímpica, foi ela a candidata e é ela que ocupa o centro das atenções. É também nos limites territoriais da cidade que ocorrerão grande parte das intervenções e é em escala local que se concentrarão os maiores impactos. Isto ajuda a explicar a grande disputa inter-cidades em torno dos Jogos a cada nova eleição da sede olímpica. Desde 
Barcelona 1992, quando se estabeleceu um novo paradigma de organização dos Jogos, a escolha das cidades sede vem mobilizando um bom número de concorrentes.

Para 2020, por exemplo, Baku, Doha, Istambul, Madri, Roma e Tóquio são postulantes. Madrid, depois da derrota para o Rio de Janeiro, permanece na disputa. A eleição se dará em 2013, durante a $125^{\text {a }}$ sessão do Comitê Olímpico Internacional (COI), em Buenos Aires. O próprio Rio de Janeiro, antes da candidatura para 2016, havia perdido a indicação para os Jogos de 2004, realizados em Atenas, e de 2012, que acontecerão em Londres. Para 2024, por sua vez, já se especulam Dubai, Paris e Toronto como pretendentes. Mas quais os motivos e o porquê de tanta antecipação? Qual o lugar ou importância dos megaeventos esportivos no contexto da economia política global e das diferentes economias locais?

$\mathrm{O}$ fato é que há um circuito internacional de megaeventos Jogos Olímpicos, Copa do Mundo FIFA, exposições internacionais etc - do qual tomam parte as cidades, cada qual buscando apresentarse ao mundo como uma cidade global, nos dizeres de Harvey (2006), como uma cidade favorável e amigável aos negócios, como um lugar seguro para se morar e visitar, para divertir-se e consumir. O urbanismo olímpico, como uma forma de empreendedorismo urbano, surge com este objetivo. Combinando a ação governamental e interesses privados, baseia-se na monumentalidade arquitetônica, na invenção de lugares e na regeneração de espaços de desvalia (MASCARENHAS, 2010; RAEDER, 2010). À exemplo de Barcelona, a expectativa é de que os Jogos imprimam à feitura das cidades sede verdadeiros saltos de inovação em produtos, serviços, estilos de vida, formas culturais e institucionais.

Além do impulso ao desenvolvimento da economia local, as inovações prometidas ou pretendidas a partir dos Jogos guardam ainda o potencial de fixarem uma imagem urbana física e socialmente atraente para as sedes olímpicas, a imagem de uma cidade adaptada à finalidade competitiva, apta a receber novos fluxos de investimentos e especulação, de produção e consumo, enfim, uma cidade ajustada às atuais formas e caminhos de acumulação de capital (HARVEY, 
2006). Os Jogos e demais megaeventos estão ligados, portanto, a uma revolução no sistema urbano, a uma nova modalidade do planejamento e ordenamento territorial, fazendo da cidade uma espécie de empresa que concorre no mercado com outras cidades empresa (VAINER, 2009; 2010).

Discutir estas questões logo de início tem o propósito de localizar o debate sobre os megaeventos no campo acadêmico. É a partir da discussão envolvendo a feitura das cidades e o desenvolvimento das metrópoles, isto é, é a partir da área da geografia e do urbanismo que percebo o maior adensamento do conhecimento produzido sobre o tema. Noções ou conceitos correntes nesta área, como empreendedorismo urbano, concorrência interurbana, empresariamento das cidades, dentre outros, conferem forma a um arcabouço categorial poderoso no sentido de reter os nexos entre a agenda urbana e a economia política, apresentando-se como balizas para os pesquisadores que pretendem se debruçar sobre as relações entre os megaeventos e as cidades ou, particularmente, entre os Jogos e o Rio de Janeiro.

Entretanto, para além do urbanismo olímpico e do debate sobre a cidade, quais as circunstâncias envolvem o projeto Rio 2016 na sua relação com o país? Os Jogos serão no Rio de Janeiro, mas como explicar o sucesso da candidatura carioca, sua construção e desdobramentos tendo em vista a realidade brasileira? Ao colocar estas perguntas, estou querendo, na verdade, chamar atenção para a necessidade de refletirmos sobre os Jogos e o país, o que, sem excluir a reflexão sobre os Jogos e a cidade, permite um melhor diálogo com a problematização inicial feita pelos editores sobre as implicações dos megaeventos na vida nacional, em especial, para a Educação Física e Ciências do Esporte.

Frequentemente, o que se ouve e se lê a partir da mídia é que o Brasil se encontra diante de uma grande janela de oportunidades. O modelo de janela de oportunidades, forjado pela ciência política a partir de Kingdon (1995), não exclui a contextualização histórica, política e econômica que envolve o surgimento de determinado tema ou problema na agenda dos governos, da mídia, do mercado etc. 
Porém, o mesmo modelo pode descambar para avaliação de que a vinda dos Jogos para o país é fruto do acaso, isto é, de uma janela de acaso, de uma combinação de fatos entrecruzados que, numa conjuntura favorável, de modo não premeditado, resultou em sucesso.

Penso que o projeto olímpico e seu êxito se inscrevem num processo histórico e relacional entre Estado e sociedade civil perpassado por relações de hegemonia e estratégias de acumulação. Com efeito, os Jogos abrem a oportunidade para que uma série de ações sejam legitimadas e desencadeadas. Mas, ainda assim, sua realização resulta de uma opção e decisão do governo brasileiro, acomodando interesses, mobilizando variados agentes, produzindo agenda e políticas públicas. Portanto, antecipo que, em minha avaliação, coube ao Estado o papel protagônico de organização do bloco de alianças e consenso necessário em torno do projeto Rio 2016, o que se articula ao modelo e orientação político-econômica do governo Lula, tema que abordaremos a seguir.

\section{A AGENDA Rı 2016}

Para dar seqüência, vou me reportar a um estudo realizado no âmbito do Programa de Pós-Graduação em Educação Física da Universidade de Brasília (UnB) (ver MASCARENHAS et al, 2011). Trata-se de uma investigação pela qual buscamos identificar agentes e avaliar as relações de hegemonia e estratégias de acumulação inerentes à candidatura do Rio de Janeiro à cidade sede dos Jogos de 2016. Sua base empírica foi inteiramente documental, construída por fontes institucionais e da mídia impressa - Ministério do Esporte (ME), COI, Comitê Olímpico Brasileiro (COB), Dossiê de Candidatura e jornal Folha de S. Paulo (FSP) -, com o levantamento de um extenso volume de dados, discutidos a partir da técnica de análise de conteúdo proposta por Bardin (2010).

Quando selecionamos as notícias publicadas na FSP em sua edição de 3 de outubro de 2009, um dia após o anúncio do Rio de Janeiro como cidade sede dos Jogos de 2016, chamaram atenção referências recorrentes ao presidente Lula e a um conjunto de outras 
personalidades, dentre as quais se destacam Jacques Rogge, presidente do COI, Arthur Nuzman, presidente do COB, Mike Lee, o marqueteiro da campanha, Eike Batista, o principal patrocinador, Orlando Silva, ministro do esporte, Sérgio Cabral e Eduardo Paes, respectivamente, o governador do Estado e o prefeito da cidade do Rio de Janeiro. Tais referências constituem um indicador da coalizão e agentes envolvidos com o projeto olímpico.

Assim, a fim de compreender o que está para além da aparência das notícias e enraizar as personalidades e seus feitos no chão da realidade histórica, buscaremos decompor a totalidade e os nexos que dinamizaram a candidatura carioca. Passamos então aos resultados da investigação realizada, apresentando-os a partir da categorização que orientou o agrupamento, tratamento e interpretação dos dados reunidos, qual seja: Estado, organização esportiva e mercado.

\subsection{Estado}

A participação estatal e o envolvimento governamental na candidatura da cidade do Rio de Janeiro a sede olímpica se definem, em certa medida, a partir da vontade e decisão política do chefe de Estado e de governo, o presidente Lula. Houve um investimento pessoal de Lula na candidatura, motivado tanto por sua paixão pelo esporte, como pela percepção da importância dos Jogos no plano das relações externas e concorrência global. O projeto Rio 2016 associava-se à perspectiva de transformação e mobilidade da nação, por isso o seu engajamento. Não por acaso, Mike Lee, marqueteiro da campanha, afirma que Lula foi o principal personagem da vitória ${ }^{1}$, pois seu prestígio e trânsito junto às organizações e lideranças internacionais agregaram enorme apoio à candidatura.

Segundo Paraná (2008), a conduta política e matrizes discursivas de Lula se forjam num esforço de emancipar os brasileiros da cultura da pobreza e, pela cultura da transformação, substituir a visão imediatista e conformada do mundo por uma ligação com o

\footnotetext{
1"Lula foi mais importante do que Blair, diz consultor". Folha de S. Paulo, 6 out. 2009
} 
futuro e com a superação dos problemas atuais. Parte de seu discurso, ao comemorar o anúncio da vitória da candidatura carioca, em Copenhague, é emblemático: "Deixamos de ser um país de segunda classe. Ganhamos a cidadania internacional"2. O projeto olímpico deve muito ao carisma, história e origem de classe do presidente, o que se soma a sua habilidade discursiva, na qual o sentido metafórico do esporte, vale lembrar, é recorrente.

Com efeito, o projeto Rio 2016 deve ser compreendido à luz do lulismo, um projeto sem rupturas e pluriclassista que incorpora representações de trabalhadores e empresários, projeto que é marcado também por uma forte identificação dos pobres - ou seja, do subproletariado - com a figura de Lula, conferindo-lhe força para mediar interesses conflitantes e apresentar suas propostas como sendo boas para todos (SINGER, 2009). No entanto, para além da vontade e empenho do líder e do mito, a candidatura olímpica está articulada a um projeto mais geral de desenvolvimento nacional, matizado pelo reposicionamento do país na geopolítica mundial e recuperação do papel do Estado.

No que se refere às relações exteriores, ao se fazer ouvir nas decisões em torno dos grandes problemas e temas da agenda internacional - reforma do Conselho de Segurança da ONU, Estados Unidos e Alca, fortalecimento do Mercosul, cooperação Sul-Sul, negociações comerciais multilaterais, G-20, aliança dos BRICS etc -, a diplomacia do governo Lula proclamou maior presença do Brasil no mundo, alçando-o à condição de potência e um autêntico global player (ALMEIDA, 2004). Neste contexto, os megaeventos acabaram por ocupar lugar de destaque. Como indicadores da atenção que mereceram os Jogos na política externa, cito: a criação, na estrutura do Itamaraty, de uma coordenação específica para tratar de cooperação esportiva; a elaboração de um plano de ações para as embaixadas brasileiras se engajarem na campanha; e, os diversos encontros bilaterais de Lula pautando o projeto Rio 2016 (RESENDE, 2010).

2"Com a Olimpíada, Brasil pode superar vira-latice". Folha de S. Paulo, 4 out. 2009.

Movimento, Porto Alegre, v. 18, n. 01, p. 39-67, jan/mar de 2012. 
Quanto à transformação interna, os Jogos são vistos como uma espécie de catalisador de obras e investimentos dinamizando a economia e fortalecendo a posição do Rio de Janeiro e do país no mercado mundial. Ainda que superestimados, os impactos sociais e econômicos esperados se articulam ao próprio projeto nacional idealizado pelos intelectuais governistas, o neodesenvolvimentismo (MERCADANTE, 2010; POCHMANN, 2009; SOUZA, 2003; dentre outros). Trata-se de um projeto ou modelo de desenvolvimento pautado na manutenção da estabilidade e ação distributiva do Estado, este último, um Estado mais forte, induzindo o crescimento e coordenando os investimentos no país a partir de estratégias de planejamento de longo prazo.

Em linhas gerais, o neodesenvolvimentismo pode ser explicado a partir de três eixos de ação, a saber: a aliança com o capital nacional pela qual, via Banco Nacional de Desenvolvimento Econômico e Social (BNDES), o governo empenhou-se em fortalecer as grandes empresas nacionais; o investimento, através do Programa de Aceleração do Crescimento (PAC); e, a recuperação da capacidade do Estado de prover políticas e programas sociais de inclusão e redução da pobreza, a exemplo do Bolsa Família. Na relação deste modelo com o projeto olímpico, num movimento combinado, enquanto o Estado investidor garante as grandes obras de infraestrutura, o Estado financiador opera na concessão de crédito aos grupos empresariais envolvidos com a construção das arenas esportivas, expansão da rede hoteleira e serviços turísticos, incremento em tecnologias de informação e telecomunicações, dentre outros setores.

Por sua vez, o Estado social, no contexto do projeto de urbanização e pacificação das favelas, o que corresponde a uma das faces do projeto olímpico, ao lado de um conjunto de outras ações governamentais, faz com que uma política intersetorial de segurança também suba os morros cariocas. Estou me referindo ao Programa Nacional de Segurança com Cidadania (PRONASCI), ao qual se articulam as políticas sociais do ME organizadas a partir do Programa Segundo Tempo (PST) - associado ao Programa Mais 
Educação, do Ministério da Educação (MEC) - e do Programa Esporte e Lazer da Cidade (PELC), com ações voltadas à juventude em conflito com a lei ou em situação de vulnerabilidade social.

Fica claro uma ação firme do governo Lula no apoio aos Jogos Rio 2016, tanto pelos compromissos assumidos de financiamento dos negócios que envolvem a preparação para o evento, como do investimento em obras de infraestrutura e incremento de programas e ações de manejo social do risco, isto é, em políticas sociais focadas na segurança da cidade. Vale advertir, no entanto, que mesmo que haja um protagonismo do Estado na organização dos Jogos, o desempenho deste papel e a própria soberania nacional esbarram nas exigências impostas pelo COI e COB.

\subsection{CoI E CoB}

É prática do COI participar da execução do projeto olímpico, impondo seu próprio plano geral de organização, seja qual for a cidade sede. Isto porque a evolução do marketing esportivo transformou os Jogos num megaevento empresarial, um empreendimento efêmero, mas enormemente lucrativo e totalmente inserido na economia política global, algo bem distante da competição limpa de interesses políticos e comerciais, voltada ao engrandecimento da cultura atlética e educação do caráter, como preconizava a tradição do ideal olímpico. "Os valores dos contratos assinados pelo COI - que tratou de centralizar a comercialização dos Jogos - cresceram em progressão geométrica e converteram os famosos cinco anéis de Coubertin numa marca mundialmente mercantilizada" (PRONI, 2004, p. 6).

Num processo de modernização conservadora, oscilando entre a tradição aristocrática e a organização empresarial, mesmo que aberto aos interesses comerciais da mídia e patrocinadores, o Movimento Olímpico e suas instituições, historicamente, organizamse como um sistema fechado e elitista, garantindo aos seus mandatários a auto-reprodução no poder (TAVARES, 2005). No entanto, a despeito da centralização, do personalismo, do clientelismo, 
dos grandes negócios e das muitas suspeitas que recaem sobre seus dirigentes, o fato é que o COI possui os direitos de imagem e propriedade intelectual das commodities culturais que envolvem o Movimento e os Jogos Olímpicos.

No contexto da globalização econômica, conforme explica Harvey (2006), os megaeventos são transformados em commodities, tipos especiais de mercadorias culturais que possuem cotação e negociabilidade globais. Assim, a singularidade e particularidade dos Jogos, identificado aqui como commodities, garante aos seus proprietários o poder monopolista e vantagem de negociação com os Estados nacionais quando da definição e contratação da sede olímpica. O Host City Contract e o Ato Olímpico colocam em evidência algumas das garantias e regras especiais para a realização dos Jogos Rio 2016.

O contrato com a cidade sede prevê, por exemplo, que o lucro dos Jogos será partilhado entre COI (20\%), COB (20\%) e Comitê Organizador dos Jogos (COJO) $(60 \%)^{3}$. Vale registrar que este último organismo, apesar de acomodar representantes dos governos federal, estadual e municipal, será presidido e controlado pelo presidente do COB. O Ato Olímpico (Lei $n^{\circ} 12.035 / 2009$ ), por sua vez, além de atribuir ao Estado responsabilidade por eventuais prejuízos, prevê que as autoridades federais atuem na fiscalização e repressão a ilícitos que infrinjam os direitos sobre as marcas e símbolos relacionados aos Jogos, bem como assegura a oferta de serviços de segurança, saúde e comunicação.

Está previsto ainda, pelo governo federal, o estabelecimento de medidas legais de caráter especial e em período específico para atender as exigências do COI para a época de preparação e realização dos Jogos. Estamos, portanto, diante de um conjunto de normas e medidas excepcionais cuja aplicação, mesmo que eventual e emergencialmente, caracterizam o Estado e a cidade de exceção. "Os megaeventos realizam, de maneira plena e intensa, a cidade de

\footnotetext{
3"Nas mãos de Nuzman". Folha de S. Paulo, 29 jul. 2010.
} 
exceção. A cidade dos megaeventos é a cidade das decisões ad hoc, das isenções, das autorizações especiais... e também das autoridades especiais" (VAINER, 2010, p. 11).

No que se refere ao financiamento, o orçamento dos Jogos prevê que as três esferas de governo repassem $\mathrm{R} \$ 1,384$ bilhão ao COJO. Esse total significa cerca de um quarto do orçamento do organismo, $\mathrm{R} \$ 5,6$ bilhões. O restante do dinheiro virá de pagamentos do COI, de patrocínios, de venda de ingressos e de licenciamento de produtos, entre outros. Mas esta é a menor fatia do orçamento, pois outros $\mathrm{R} \$ 23,2$ bilhões estão previstos em investimentos públicos em infraestrutura (COMITÊ RIO 2016, 2009), investimentos a serem coordenados pela Autoridade Pública Olímpica (APO), um consórcio dos governos municipal, estadual e federal cuja criação se deu por exigência do COI para facilitar a fiscalização sobre seu plano de organização $0^{4}$.

\subsection{MERCADO}

Na conta que envolve os gastos para realização dos Jogos deve ser somado ainda o valor de $\mathrm{R} \$ 138$ milhões referente ao custo da candidatura. Mais uma vez foi o fundo público a fonte da maior parte dos recursos, $R \$ 101$ milhões. O restante, veio da iniciativa privada, R\$ 37 milhões, patrocinados pelo Bradesco, Odebrecht, TAM, Embratel e Grupo EBX ${ }^{5}$. De acordo com Boito Jr. (2005), o projeto neodesenvolvimentista do Governo Lula - ou liberaldesenvolvimentista, conforme prefere denominá-lo - traduz-se por um modelo de desenvolvimento sem rupturas e pluriclassista, ancorado na parceria com a grande burguesia nacional, o que, obviamente, repercute no projeto olímpico.

O principal financiador da campanha foi o empresário Eike Batista. Foram investidos R \$23 milhões através do Grupo EBX, de sua propriedade. Considerado o "mecenas" dos Jogos, o empresário

\footnotetext{
4"Autoridade Olímpica terá formato de consórcio". Folha de S. Paulo, 19 mar. 2010.

5"Campanha já consumiu R\$ 138 mi". Folha de S. Paulo, 2 out. 2009.
}

Movimento, Porto Alegre, v. 18, n. 01, p. 39-67, jan/mar de 2012. 
mais rico do país parece ter sido também o mais interessado na vitória carioca ${ }^{6}$. Suas empresas possuem vários negócios no Rio de Janeiro. Na construção do porto de Açu, por exemplo, o investimento previsto é de cerca de R $\$ 3$ bilhões, mas o início das obras esbarra ainda na concessão de uma série de licenças governamentais. Outros investimentos envolvem as áreas de petróleo, mineração, energia, empreendimentos imobiliários e serviços, com destaque para hotelaria, turismo, alimentação e entretenimento ${ }^{7}$.

O Bradesco se responsabilizará pelos seguros e serviços financeiros dos Jogos, bem como já lançou uma série de fundos para aplicação em ações de empresas que tendem a se beneficiar com o evento, projetando ganhos na Bolsa a partir de papéis de companhias de infraestrutura e logística, siderurgia, energia elétrica, saneamento, telecomunicação, transportes, indústria de base e construção $\operatorname{civil}^{8}$. A Odebrecht, que havia liderado o consórcio que realizou as reformas do Maracanã e a construção do estádio do Engenhão no Pan 2007, está interessada na infraestrutura esportiva a ser construída ${ }^{9}$. A TAM foi a responsável pelo transporte aéreo dos dirigentes do Comitê Rio 2016 ${ }^{10}$. Por fim, a Embratel, ao patrocinar a campanha, credencia-se como possível fornecedora dos serviços de telecomunicações necessários ${ }^{11}$.

Vale também registrar a contratação das consultorias internacionais. A principal delas foi a de Mike Lee. Sua campanha de marketing funcionou tanto para fortalecer competitivamente a candidatura, como serviu de instrumento de legitimação, produzindo consensos e mobilizando o orgulho cívico, apresentando o projeto olímpico como expressão da própria vontade geral da nação. No entanto, o que se organizará sob a aparência do espetáculo esportivo

\footnotetext{
6"Mecenas do Rio, Eike cede jato a políticos". Folha de S. Paulo, 30 set. 2009.

${ }^{7}$ Informações disponíveis em: http://www.ebx.com.br/grupoebx.php. Acesso em: 13 set. 2010.

8"Fundos visam ganhos com Copa e Olimpíada". Folha de S. Paulo, 5 jul. 2010.

9"Rio-2016 anuncia apoio de empreiteira". Folha de S. Paulo, 2 jun. 2009.

10"Campanha se norteia por viagens". Folha de S. Paulo, 28 ago. 2009.

11"Campanha já consumiu R\$138 mi". Folha de S. Paulo, 2 out. 2009.
} 
é um verdadeiro balcão de negócios, como diz Harvey (2006), um "mercado-livre festivo" que combina projetos hegemônicos e estratégias de acumulação. Através dos setores de atuação empresarial representados pelos patrocinadores, configura-se um quadro tendencial das parcerias e frações da burguesia a serem privilegiadas.

\subsection{O BLOCO OLÍMPICO}

O exposto até aqui denota a formação de uma coalizão que transcende ao poder estatal, aglutinando interesses do COI, COB e mercado. Configura-se, assim, o que podemos chamar de bloco olímpico, ou seja, o bloco de poder inerente à organização dos Jogos Rio 2016. Na teoria do Estado, mais especificamente na obra de Poulantzas (2000), a noção de bloco de poder permite identificar o favorecimento dos interesses socioeconômicos de uma ou mais frações da classe dominante em detrimento de outras frações, considerando tanto sua ação política como a posição particular que ocupa no processo de produção num momento e situação determinados. Assim, o Estado se constitui como agente organizador da hegemonia de dadas frações de classe no seio do bloco de poder.

No modelo desenvolvimentista do governo Lula, coube ao Estado apoiar as grandes empresas nacionais no sentido de lhes conferir competitividade no mercado mundial. Segundo Boito Jr (2005), não houve ruptura, ao contrário, a aliança com a grande burguesia e o fortalecimento do capital nacional privado constitui um dos traços definidores do bloco de poder e modelo de desenvolvimento conduzido e organizado pelo governo de Lula.

No que toca ao esporte, os parceiros de interação do Estado, bem como a estrutura e ordem definidoras das políticas públicas para o setor, sempre foram dadas por um sistema verticalizado de cima para baixo, a partir das entidades de administração (BRACHT, 1997; MANHÃES, 2002). A chegada do Partido dos Trabalhadores (PT) ao Estado também não trouxe ruptura com o status quo da área, pois o pragmatismo impediu qualquer possibilidade de debate programático em torno do setor. Segundo Castellani Filho (2009), 
em busca de legitimidade no setor esportivo, o ME, cuja direção foi terceirizada pelo PT ao Partido Comunista do Brasil (PC do B), desenvolveu uma postura de servidão voluntária às entidades de administração, COB e CBF, o que resultou no alinhamento das políticas para o setor aos interesses da fração conservadora do campo esportivo.

\subsection{O BRASIL ENTRE OS 10 MAIS}

O sucesso da candidatura carioca resultou de uma coalizão de forças cujas pretensões e interesses, trabalhados pelo marketing, repercutiram como a própria vontade geral de toda a sociedade ou nação. Além de ter reforçado a condição de Lula como condottiere e mito, o projeto olímpico se articulou ao projeto de governo, ao modelo neodesenvolvimentista e à política externa de reposicionamento do país na geopolítica mundial. Ancorou-se, por um lado, numa política conservadora de aproximação e subordinação do Estado brasileiro às entidades proprietárias dos Jogos, COI e $\mathrm{COB}$, e, por outro, num projeto empreendedor orientado para o mercado que combina projetos hegemônicos e estratégias de acumulação.

A agenda Rio 2016 exclui, portanto, a participação popular e o controle democrático. O projeto olímpico, por exemplo, foi construído de cima para baixo, verticalizado a partir do $\mathrm{COB}$ e representantes de governo, sem qualquer discussão junto à sociedade civil. Como adverte Castelan (2010), a determinação de trazer os Jogos para o Brasil não se sustenta nas Conferências Nacionais do Esporte (BRASIL, 2004; 2006), tampouco na Política Nacional do Esporte (BRASIL, 2005). É no pós Pan 2007 que se nota a virada na postura governamental rumo ao megaeventos esportivos. Há o redirecionamento das ações do $\mathrm{ME}$, antes orientadas por uma agenda de viés social vinculada ao discurso de democratização do acesso à prática esportiva via PST, até então, o programa de propaganda desta pasta ministerial (ATHAYDE; MASCARENHAS, 2010).

A III Conferência Nacional do Esporte (CNE), realizada no primeiro semestre de 2010, evidencia tal virada. Depois de pautar- 
se pelos temas "Esporte, Lazer e Desenvolvimento Humano" (I CNE, 2004) e "Construindo o Sistema Nacional de Esporte e Lazer" (II CNE, 2006), a III CNE apresentou para discussão o "Plano Decenal de Esporte e Lazer" que, subordinado ao slogan "Por um time chamado Brasil", foi construído a partir de metas e ações em torno de "10 pontos em 10 anos para projetar o Brasil entre os 10 mais" (BRASIL, 2010a). É certo que os megaeventos já constituíam o princípio organizador da agenda esportiva nacional antes mesmo da realização da III CNE, uma vez que a candidatura do Rio de Janeiro data de 2006, mas este espaço acaba por conferir legitimidade às políticas em curso.

Vejamos os 10 pontos para projetar o Brasil entre os 10 mais:

[1] Promover a inclusão social e o desenvolvimento humano por meio de programas socioesportivos; [2] Institucionalizar o esporte educacional; [3] Atingir resultados inéditos nas competições e assim projetar o Brasil no ranking do alto rendimento; [4] Incrementar nossa infraestrutura esportiva; [5] Modernizar e valorizar o futebol como identidade cultural do Brasil; [6] Ampliar o leque de modalidades para diversificar a prática esportiva no país; [7] Qualificar a gestão do esporte e do lazer; [8] Aproveitar o potencial econômico-social dos grandes eventos, porque contribuem com o desenvolvimento nacional gerando milhões de empregos, aumentando a renda e propiciando o renascimento de áreas urbanas, a melhoria da qualidade de vida, a oferta de perspectivas à juventude e o fortalecimento do respeito do mundo por nossa pátria; [9] Valorizar o trabalhador da área, especialmente o profissional de educação física, garantindo postos de trabalho; [10] Estabelecer a criação de políticas de formação continuada e permanente, de desenvolvimento científico e tecnológico e de acompanhamento e avaliação dos programas, resultando na profissionalização cada vez maior da política esportiva no país (BRASIL, 2010b, p. 2, grifo meu).

Movimento, Porto Alegre, v. 18, n. 01, p. 39-67, jan/mar de 2012. 
Dentre as ações projetadas, destaco a 2 e a 9, relativas ao esporte educacional e ao profissional de Educação Física. Ao chamar atenção para tais ações, passo à discussão sobre os prováveis impactos dos Jogos Rio 2016 na escola.

\section{Impactos para a Educação Física}

Em tempos de Jogos, são recorrentes os discursos em defesa da valorização da Educação Física. Esta dinâmica já foi constatada por Bracht e Almeida (2003), ao problematizarem o movimento pró Educação Física que se seguiu ao fracasso brasileiro no pós Sydney 2000. Governo federal, COB e Conselho Federal de Educação Física (CONFEF), alegando a necessidade de melhor organização da base de desenvolvimento do esporte nacional, proclamaram a revalorização da Educação física - leia-se, das práticas esportivas - na escola, o que redundou, segundo advertiram os autores, numa peseudovalorização da Educação Física.

A retórica reedita um discurso a muito presente na
Educação Física brasileira, qual seja, a retomada da
idéia de pirâmide esportiva, subordinando, mais uma
vez, o desporto escolar àquilo que é de interesse do
esporte de alto rendimento, tornando perceptível o
corte, já denunciado, da perda do projeto político-
pedagógico da Educação Física para o esporte de
rendimento. Em outras palavras, a subordinação da
Educação Física à política esportiva (BRACHT;
ALMEIDA, 2003, p. 94).

Não sou um pesquisador da temática da Educação Física escolar. Portanto, penso que o que tenho a dizer pouco acrescenta ao debate sobre o processo de peseudovalorização já assinalado. Busco apenas registrar como tal retórica vem se atualizando e se amplificando nos últimos anos, mantendo sintonia com a agenda Rio 2016 e com os objetivos de se projetar o Brasil entre os 10 mais. A leitura de alguém que tem se dedicado aos estudos sobre as políticas de esporte e lazer e, particularmente, acompanhado as ações do $\mathrm{ME}$, pode agregar novas elementos de interpretação e compreensão 
de como tal discurso se articula aos interesses e relações de hegemonia que perpassam a área da Educação Física e o setor esportivo.

Meu pressuposto é que se a cada novo ciclo olímpico, ainda que com diferentes nuances, o discurso da valorização da Educação Física está presente, o diferencial agora parece ser a defesa da valorização estendida ao profissional de Educação Física. Se o que está no escopo da ambição olímpica do governo brasileiro, na verdade, é a massificação da prática esportiva a partir do ambiente escolar, e não propriamente a qualificação da disciplina pedagógica Educação Física, não é de se estranhar o abandono do professor em detrimento do profissional. Esta inflexão, em minha análise, resulta das reivindicações coorporativas e do poder político que o CONFEF, representante e guardião cartorial da profissão, vêm amealhando junto ao Estado e à organização esportiva.

Para desenvolver a discussão, vou me reportar a dois pronunciamentos, dois conjuntos de promessas, dois eventos e dois documentos. Os pronunciamentos são do ministro do Esporte, Orlando Silva, e do presidente do CONFEF, Jorge Steinhilber. As promessas constam do Dossiê de Candidatura Rio 2016 e da proposta para o setor esportivo da então presidenciável, Dilma Rousseff. Os eventos são o "Seminário Educação Física e Esporte Escolar: da formação a competição" e o "II Encontro Nacional de Gestores de Educação: a Educação Física na educação básica", com os respectivos documentos produzidos em cada um destes espaços, o "Documento preliminar indicativo para ações de políticas públicas para Educação Física e esporte escolar" e a "Carta de Brasília". Uma análise dos sinais metadiscursivos inerentes a parte destes registros pode jogar luzes sobre as tendências que se avizinham.

Comecemos com os pronunciamentos, a iniciar com uma problematização do ministro do Esporte, sobre o distanciamento entre o esporte e a escola no Brasil:

Para Londres ganhar o direito de organizar os Jogos de 2012, foi muito importante o trabalho que fez nas escolas. Esse foi um dos pilares da candidatura.

Movimento, Porto Alegre, v. 18, n. 01, p. 39-67, jan/mar de 2012. 
(...) O Brasil pode aprender com Londres. Não existe alternativa para massificar a prática de esporte a não ser associá-lo à educação ${ }^{12}$.

O segundo, cujo conteúdo metafórico inspirou o título deste texto, é do presidente do CONFEF.

O Brasil está envolto em um verdadeiro tsunami esportivo. (...) Acreditamos que governantes, parlamentares, empresas e demais atores deveriam atentar para a forma de "surfar" neste tsunami. (...) A bola da vez é o Esporte, e o Profissional de Educação Física é o responsável para que seus valores sejam adquiridos e assimilados. É o responsável pelo seu desenvolvimento desde a base até o alto rendimento ${ }^{13}$.

As promessas sinalizam o tratamento dispensado à Educação Física em duas campanhas, a primeira referente à candidatura do Rio de Janeiro à cidade sede. Conforme previsão constante do Dossiê de Candidatura, diversos legados econômicos, sociais, urbanos, ambientais e esportivos são anunciados como saldo e consequiência direta da realização dos Jogos. Para o tema da juventude e da educação, são fixadas as seguintes metas:

Ampliação do PST, com o atendimento saltando de 1 milhão para 3 milhões de jovens, além do investimento de 400 milhões de dólares no Programa Mais Educação e duplicação do número de participantes nos Jogos Estudantis Brasileiros (JEB's) e Jogos Universitários Brasileiros (JUB's), estimando a formação de 5 milhões de atletas (COMITÊ RIO 2016, 2009).

O segundo conjunto de promessas é relativo à campanha das eleições presidenciais de 2010, na qual a então candidata, Dilma Rousseff, apresentou quatro propostas básicas para a área do esporte:

\footnotetext{
12"Candidatura a 2016 pode mudar até educação física". Folha de S. Paulo, 18 mar. 2008. 13"O Brasil está envolto em um verdadeiro tsunami esportivo". Revista E.F., n. 40, jun. 2011.
} 
Implantar ou reformar quadras esportivas em 10 mil escolas públicas em diferentes regiões do Brasil; construir 800 complexos de esporte e lazer no país [Praças do PAC e/ou Praças dos Esportes e da Cultura]; ampliar o programa Bolsa Atleta; e, implantar ações de valorização do profissional de Educação Física ${ }^{14}$.

Além da continuidade das ações do governo Lula, em particular, das ações protagonizadas pelo $\mathrm{ME}$, tais propostas mais uma vez colocam em evidência o profissional de Educação Física. Ainda que esta suposta valorização, em diversos aspectos, seja questionável, sua incorporação ao discurso de governo e, em especial, da presidenciável governista, é algo que reflete os avanços que o CONFEF tem obtido em sua capacidade de influenciar políticas públicas para o setor esportivo, sem desconsiderar sua penetração junto a setores como a educação e a saúde. Ocorre que as reivindicações do conselho profissional da Educação Física inscrevem-se na estrutura e organização do Estado fazendo-se representar por vários de seus agentes e pessoal, espraiando-se por diferentes órgãos de governo, alcançando também os níveis estaduais e municipais, o poder executivo e o legislativo.

O poder político e a receptividade do Conselho podem ser exemplificados pelo primeiro dos dois eventos citados. Trata-se do "Seminário Educação Física e Esporte Escolar: da formação a competição", realizado em 2009 pela Comissão de Turismo e Desporto da Câmara dos Deputados, em Brasília. Além de abrigar o lançamento da campanha nacional do Conselho, intitulada "Educação Física escolar - plantando cultura, cidadania e saúde", o seminário teve o objetivo de debater a Educação Física nos currículos escolares brasileiros. O resultado apresentado foi o "Documento preliminar indicativo para ações de políticas públicas para Educação Física e esporte escolar", subscritos pela Câmara dos Deputados, MEC e ME (BRASIL, 2010c).

\footnotetext{
${ }^{14 " C o n h e c ̧ a ~ a s ~ p r i n c i p a i s ~ p r o p o s t a s ~ d e ~ c a m p a n h a ~ d e ~ D i l m a ~ R o u s s e f f " . ~ F o l h a ~ d e ~ S . ~ P a u l o, ~} 1$ dez. 2010
}

Movimento, Porto Alegre, v. 18, n. 01, p. 39-67, jan/mar de 2012. 
Cabe assinalar que ambos os ministérios, da educação e do esporte, recusaram-se a dar divulgação a outro documento produzido alguns anos antes e que teve finalidade semelhante, ou seja, estabelecer diretrizes políticas para o desenvolvimento da educação física escolar na educação básica. Trata-se da "Carta de Brasília", resultante do segundo evento ao qual quero me reportar, o "II Encontro Nacional de Gestores de Educação (ENGE): a Educação Física na educação básica".

O I ENGE foi organizado pelo próprio MEC, em 2004, com a colaboração do $\mathrm{ME}$, propondo a retomada da discussão sobre a educação física escolar no âmbito federal. Atendendo as demandas deste encontro, foi criado um grupo de discussão sobre a Educação Física escolar, coordenado pelo MEC e com a participação de representantes do ME, do Colégio Brasileiro de Ciências do Esporte (CBCE) e de pesquisadores da área. Por conseguinte, o grupo apontou para a necessidade de dar continuidade às discussões. Foi construído então em 2006 o II ENGE, em Brasília, buscando aprofundar o debate sobre Educação Física escolar e viabilizar o diálogo entre os sistemas públicos de educação e os pesquisadores da área.

A minuta da "Carta de Brasília", além de sistematizar um conjunto de diretrizes de ação para a qualificação da Educação Física Escolar - identificando os desafios para os agentes e o pessoal da educação básica, das universidades e do MEC ante tal propósito -, problematizou a pseudovalorização da Educação Física conduzida pelas políticas do ME e questionou a ingerência do CONFEF no âmbito da escola, propondo:

Consulta junto ao CNE sobre a legalidade da exigência do registro profissional em concursos públicos para o magistério em Educação Física; Debate qualificado acerca das relações estabelecidas entre a Educação Física (componente curricular) e o Esporte Educacional (atividade complementar ao fazer escolar) à luz das tensões e contradições que o ethos do alto rendimento faz acontecer no interior dos sistemas de educação; Definição de 
responsabilidades e restrições quanto à atuação do MEC e do ME no âmbito dos sistemas públicos de educação com destaque para ações relativas aos jogos escolares ${ }^{15}$.

Não cabe aqui desdobrar os motivos, mas o fato é que este documento nunca veio a ser publicizado pelo MEC, sendo que pouco mais de dois anos depois, como anteriormente dito, junto com o ME, a pasta subscreve o "Documento preliminar indicativo para ações de políticas públicas para Educação Física e esporte escolar", cuja orientação é diametralmente oposta à "Carta de Brasília". Uma avaliação do primeiro documento, produzida em 2009 no âmbito da direção nacional do CBCE e do grupo organizador do ENGE, ajuda no esclarecimento daquilo que está em disputa quanto à concepção de Educação Física.

Há uma série de passagens do documento - "da formação à competição", "carga horária para treinamento do esporte", "definição de um modelo de um sistema de jogos e competições escolares" que indicam para a pirâmide esportiva, concepção ausente dos dispositivos institucionais do sistema educacional brasileiro, como, por exemplo, dos Parâmetros Curriculares do Ensino Fundamental e Médio, das Diretrizes para a Formação de Professores da Educação Básica etc. Tal ausência se justifica porque tal concepção, baseada no modelo do esporte de alto rendimento, opõe-se à consolidação dos valores ético-políticos perseguidos pela instituição escolar, desprezando todos os demais conteúdos da cultura corporal e acúmulo mais recente das formulações didático-metodológicas para o trato pedagógico do esporte.

Ademais, todo documento apresenta um equívoco conceitual e legal em sua formulação, ao dizer que o profissional de Educação Física é responsável pela disciplina curricular obrigatória Educação Física. Isto acontece porque "aulas de Educação Física e de Esporte Escolar", no documento, são tomados como sinônimos. Como se não bastasse, a orientação do CONFEF é pelo enquadramento dos

\footnotetext{
${ }^{15} \mathrm{~A}$ minuta da "Carta de Brasília" foi posteriormente divulgada pelo CBCE. Disponível em: http:/ /www.cbce.org.br/br/acontece/materia.asp?id=737. Acesso em: 30 jun. 2011.
} 
Jogos Escolares e Universitários à Lei nº 9.696/1998, que regulamenta a profissão ${ }^{16}$. Para o conselho, tanto a orientação de equipes esportivas em situação de Jogos como o desenvolvimento do esporte escolar é prerrogativa do profissional de Educação Física, e não do professor.

Há de se dizer que os objetivos da Educação Física devem ser os objetivos da escola e não de políticas e interesses transitórios e externos à sua realidade, como o demandado pelos megaeventos esportivos, em especial, pelo projeto olímpico. Deste modo, o esporte não pode ser confundido com Educação Física, mas deve ser compreendido apenas como um dos seus elementos, junto com a ginástica, o jogo, a dança, a luta, dentre outras práticas corporais produzidas pela humanidade. Mas esta não é a visão que prevalece entre os agentes e o pessoal do Estado, a visão que prevalece no seio do bloco de poder.

Deste modo, a retomada da idéia de pirâmide esportiva e os perigos quanto à perda do projeto político-pedagógico da Educação Física para o esporte de rendimento, mais do que retórica e discurso, além de constituírem o cimento ideológico do bloco olímpico, ganham o contorno de política oficial. Das promessas realizadas, depreendese como tendência um maior investimento do Estado no esporte escolar, o que se traduz pela ampliação da infraestrutura - através da construção de quadras -, a ampliação do número de bolsas para atletas estudantis, o crescimento do PST-Mais Educação - tanto no sentido da massificação da prática esportiva, da detecção de talentos e do manejo social do risco - e o incremento dos JEBs. Se não no todo, avalio que boa parte destas promessas vá sim chegar ao chão da escola, ainda que de modo geograficamente desigual.

Por sua vez, agente funcional ao status quo da área, como se esta posição fosse expressão da própria vontade geral da Educação Física brasileira, o conselho profissional endossa e busca se beneficiar

\footnotetext{
${ }^{16}$ Informação disponível em: http://www.confef.org.br/extra/noticias. Acesso em: 5 set. 2011.
} 
das políticas decorrentes da agenda Rio 2016. Parceiro de primeira hora nas ações do $\mathrm{ME}^{17}$, condutor da tocha olímpica no Pan $2007^{18}$, agraciado pelo COB em 2009 com o título de presidente da Academia Olímpica Brasileira (AOB) ${ }^{19}$, Jorge Steinhilber, presidente do Conselho, personifica a aderência do CONFEF ao bloco olímpico.

Enfim, evidenciados alguns dos prováveis impactos e legados dos megaeventos esportivos - em particular, dos Jogos Rio 2016 - no contexto da Educação Física. Vale mencionar que não subestimo a capacidade reativa e poder refratário dos professores e da escola em relação ao projeto olímpico. Quero dizer com isso que, como contradição em processo, as políticas e ações governamentais voltadas ao esporte escolar, com rebatimento para a disciplina pedagógica Educação Física, podem até ser bem recebidas, dada a escassez de estrutura e recursos do sistema público de ensino, mas podem também ser parcial ou totalmente re-significadas. Sua concretização e efetividade estará condicionada à experiência comum compartilhada pelos sujeitos da escola, que podem se contrapor aos valores e interesses propagados pelo ME e MEC.

\section{PAPEL DAS CIÊNCIAS DO ESPORTE}

Quando soa um alerta de tsunami, as recomendações são para afastar-se das cidades costeiras ou buscar refúgio em lugares mais altos e seguros. No caso da Educação Física, a despeito do alerta, a pseudovalorização de sua inserção no ambiente escolar, bem como

\footnotetext{
${ }^{17}$ Desde 2006, no início da gestão de Orlando Silva a frente da pasta, Jorge Steinhilber já manifestava total apoio às ações do ME. "Conselho de Educação Física reforça papel do Segundo Tempo". Portal de notícias do ME, 11 abr. 2006. Um exemplo da parceria entre CONFEF e ME na linha da legitimação ideopolítica dos megaeventos consiste na realização, em 2008, do "Seminário Gestão de Legados de Megaeventos Esportivos", cujos debates resultaram em publicação sobre legados organizada por Rodrigues et al (2008).

${ }^{18 " C O N F E F ~ e ́ ~ c o n v i d a d o ~ p e l o ~ M i n i s t e ́ r i o ~ d o s ~ E s p o r t e s ~ p a r a ~ b u s c a r ~ o ~ f o g o ~ d o ~ P a n-a m e r i c a n o ~ n o ~}$ México". Revista E.F., n. 24, jun. 2007

${ }^{19}$ Fundada em 1998, "a AOB tem o objetivo de desenvolver a educação olímpica por meio de estudos e pesquisas realizados em instituições acadêmicas do Brasil e do exterior". Segundo seu estatuto, sua diretoria é indicada pelo presidente do COI. Jorge Steinhilber ocupa sua presidência desde 2009. Disponível em http://www.cob.org.br/pesquisa_estudo/academia.asp. Acesso em 3 set. 2011.
} 
a pseudovalorização de seus profissionais, já é um processo em curso. $\mathrm{O}$ fato é que, como uma seqüência de ondas poderosas, os megaeventos tendem a, de uma forma ou de outra, impactar a área. Não penso num manual de sobrevivência, mas há a necessidade de aprofundar estudos sobre o tema, sobre os megaeventos e a Educação Física, o que torna indispensável a ação acadêmica e política de seus agentes e instituições científicas.

Neste sentido, quando me refiro ao papel das Ciências do Esporte, estou me referindo, em verdade, ao papel dos pesquisadores da área da Educação Física e do CBCE. Registro, assim, dois apontamentos. O primeiro diz respeito ao aprofundamento das reflexões e capacidade de leitura crítica dos megaeventos esportivos, preocupação que deve ocupar cada vez mais a nossa agenda de pesquisa e de debates. Isto significa problematizar não só o seu impacto ou relações com a escola, mas também com as práticas corporais e a saúde, o meio ambiente, a comunicação e a mídia, o corpo e a cultura, a formação profissional, os movimentos sociais, as políticas públicas, a inclusão e a diferença, o próprio desempenho e treinamento etc.

Em tempos de megaeventos, será preciso travar uma verdadeira batalha das idéias em torno dos interesses e projetos hegemônicos que se articulam a partir do esporte e para a Educação Física. Para tal, temos de ter o cuidado com a desinformação, e o denuncismo que cercam a organização de tais eventos. A arma da crítica não pode prescindir de uma análise em profundidade e totalidade, evitando as palavras de ordem e os discursos prontos. Ademais, precisamos saber medir nossa força política e agir estrategicamente.

Sem abandonar a pauta da Educação Física escolar que, malgrado a iniciativa de parceria com o MEC e ME, pode ser retomada a partir do envolvimento de outros agentes e instituições como, por exemplo, os sindicatos da base dos trabalhadores em educação -, a disputa pelo fundo público pode ser uma ação estratégica importante, pressionando por mais recursos para o desenvolvimento científico da área. "O orçamento público é um espaço de luta política, onde as diferentes forças da sociedade buscam inserir seus interesses" 
(SALVADOR, 2010, p. 607). Por isso, a disputa em torno do orçamento do setor esportivo, ao mesmo tempo em que se constitui como fator de deslegitimação do bloco de poder inerente à organização dos megaeventos, pode ampliar a estrutura e fomento da produção científica e tecnológica voltada ao Esporte e Lazer e à Educação Física.

Embora a CNE, em suas três edições (BRASIL, 2004; 2006; 2010a) tenham recomendado a promoção do desenvolvimento científico e tecnológico no setor esportivo, a instabilidade da estrutura, do calendário e do financiamento tem comprometido a organização e manutenção das redes de pesquisa fomentadas pelo ME, gerando dificuldades em seus processos de sua consolidação. Neste caso, um desafio posto para o CBCE, é questionar as políticas decorrentes da organização dos megaeventos, reivindicando a estruturação de uma Política de Ciência, Tecnologia e Inovação em Esporte e Lazer como uma política do ME e do Estado brasileiro ${ }^{20}$.

\footnotetext{
${ }^{20} \mathrm{Em}$ outros espaços de discussão - "Seminário Nacional de Políticas de Esporte e Lazer" e "Fórum Permanente de Pós-Graduação em Educação Física do CBCE" - tive a oportunidade de apresentar argumentos em favor de uma Política de Ciência, Tecnologia e Inovação em Esporte e Lazer, identificando as bases para sua formulação, os desafios para sua implementação e propostas iniciais para seu desenvolvimento. Ver: Mascarenhas (2010).
} 
Sports mega-events and Physical Education: Tsunami alert

Abstract: This paper analyzes the impact of sports mega-events in different areas of the national reality. Meanwhile, from the relational state, sports organization and market, discusses the relations of hegemony and accumulation strategies related to the Rio 2016 agenda. It also presents a discussion of how the Physical Education and Sport Sciences fall in this process, recording some notes to its agents and academic and scientific institutions.

Keywords: Mega Events sports, public policy, physical education.

Megaeventos deportivos y Educacion Física: Alerta de Tsunami

Resumen: Este trabajo analiza el impacto de los megaeventos deportivos en las diferentes áreas de la realidad nacional. Mientras tanto, desde la relacional Estado, organización deportiva y mercado, analiza las relaciones de hegemonía y las estrategias de acumulación involucrado en la agenda Rio 2016. También se presenta una discusión de cómo la Educación Física y Ciencias del Deporte que caen en este proceso, registrando algunas notas a sus agentes y las instituciones académicas y científicas.

Palabras clave: Megaeventos deportivos; políticas públicas; educación física. 


\section{REFERÊNCIAS}

ALMEIDA, Paulo Roberto. Uma política externa engajada: a diplomacia do governo Lula. Revista Brasileira de Política Internacional, Brasília, v. 47, n. 1, p. 162 184, jan./jun., 2004.

ATHAYDE, Pedro Fernando Avalone; MASCARENHAS, Fernando. Políticas sociais de esporte e lazer: uma análise do programa Segundo Tempo no Distrito Federal. In: ALMEIDA, Dulce Filgueira de Almeida et al (Org.). Política, lazer e formação. Brasília: Thesauros, 2010.

BARDIN, Laurence. Análise de conteúdo. 4 ed. Lisboa: Edições 70, 2010.

BRACHT, Valter. Sociologia crítica do esporte: uma introdução. Vitória: UFES, CEFD, 1997.

BRACHT, Valter; ALMEIDA, Felipe Quintão de. A política de esporte escolar no Brasil: a pseudovalorização da educação física. Revista Brasileira de Ciências do Esporte, Campinas, v. 24, n. 3, p. 87-101, mai. 2003.

BRASIL. I Conferência Nacional do Esporte: documento final. Brasília: Ministério do Esporte, 2004.

Política Nacional do Esporte. Brasília: Ministério do Esporte, 2005.

II Conferência Nacional do Esporte: caderno de resoluções. Brasília: Ministério do Esporte, 2006.

III Conferência Nacional do Esporte: texto básico. Brasília: Ministério do Esporte, 2010a.

. III Conferência Nacional do Esporte: carta de Brasília. Brasília: Ministério do Esporte, 2010b.

Educação física e esporte escolar: da formação a competição. Brasília: Câmara dos Deputados, 2010c.

CASTELAN, Lia Polegato. As Conferências Nacionais do Esporte na configuração da política esportiva e de lazer no governo Lula (2003-2010). 2010. Dissertação (Mestrado) - Programa de Pós-Graduação em Educação Física, Faculdade de Educação Física, Unicamp, Campinas, 2010.

CASTELLANI FILHO, Lino. O PT, a política esportiva brasileira e a síndrome de Estocolmo. Campinas, 2009. Disponível em: <http:// www.observatoriodoesporte.org.br.> Acesso em: 5 nov. 2010.

COMITÊ RIO 2016. Rio 2016: cidade candidata. Dossiê de candidatura. Rio de Janeiro: COB, 2009. 
HARVEY, David. A produção capitalista do espaço. 2 ed. São Paulo: Annablume, 2006.

KINGDON, John W. Agendas, alternatives and public policies. 2 ed. New York: Harper Collins College, 1995.

MANHÃES, Eduardo Dias. Políticas de esportes no Brasil. 2. ed. Rio de Janeiro: Paz e Terra, 2002.

MASCARENHAS, Fernando. Os megaeventos esportivos e os impactos desejados nas políticas públicas: perspectiva acadêmica. In: PINTO, Leila Mirtes Santos de Magalhães; UVINHA, Ricardo Ricci; COSTA, Eduardo Tadeu (Org.). Brasil 2016: a olimpíada e os impactos desejados nas políticas públicas de esporte e lazer das cidades brasileiras. São Bernardo do Campo: Domaguil, 2010

MASCARENHAS, Fernando. et al. O bloco olímpico: Estado, organização esportiva e mercado na configuração da agenda Rio 2016. [S.I.: s.n.], 2011.

MASCARENHAS, Gilmar. Barcelona y Río de Janeiro: diálogo entre modelos y realidades del llamado urbanismo olímpico. Biblio 3w, Barcelona, v. 15, p. 1-6, nov. 2010.

MERCADANTE, Aloizio. O governo Lula e a construção de um Brasil mais justo. São Paulo: Fundação Perseu Abramo, 2010.

PARANÁ, Denise. Lula, o filho do Brasil. 3 ed. São Paulo: Fundação Perseu Abramo, 2008.

POCHMANN, Marcio. O emprego no desenvolvimento da nação. São Paulo: Boitempo, 2009.

POULANTZAS, Nicos. O Estado, o poder, o socialismo. 4 ed. São Paulo: Paz e Terra, 2000.

PRONI, Marcelo Weishaupt. A metamorfose dos jogos olímpicos (1896-1996). In: Encontro Regional de História, 17., 2004, Campinas. Anais...

RAEDER, Sávio. Jogos e cidades: ordenamento territorial em sedes de megaeventos esportivos. Brasília: Ministério do Esporte, 2010.

RESENDE, Carlos Augusto Rollemberg de. O Esporte na política externa do governo Lula: o importante é competir? Meridiano 47, Brasília, v. 11, n. 122, p. 35-41, nov./ dez. 2010.

RODRIGUES, Rejane Penna; PINTO, Leila Mirtes Magalhães; TERRA, Rodrigo; DA COSTA, Lamartine Pereira. (Orgs.). Legados de megaeventos esportivos. Brasília: Ministério do Esporte, 2008.

SALVADOR, Evilásio. Fundo público e políticas sociais na crise do capitalismo. Serviço Social \& Sociedade, São Paulo, n. 104, p. 605-131, out./dez. 2010. 
SINGER, André. Raízes sociais e ideológicas do lulismo. Novos Estudos, São Paulo, 85, p. 83-102, nov. 2009.

SOUZA, Lula Renildo. Neodesenvolvimentismo e o governo. Princípios, São Paulo, n. 69 , p. $18-28$, mai. 2003.

TAVARES, Otávio. Comitê Olímpico Internacional. In: GONZÁLEZ, Fernando Jaime; FENSTERSEIFER, Paulo Evaldo. (Orgs.). Dicionário crítico de educação física. ljuí: Unijuí: 2005.

VAINER, Carlos. Rio 2016: um jogo (Olímpico?) de cartas marcadas. Jornal dos Economistas, Rio de Janeiro, n. 245, p. 3-4, dez. 2009.

. Megaeventos e cidade de exceção. In: International Conference MegaEvents and the City, 2010, Niterói. Anais...

Endereço para correspondência:

Fernando Mascarenhas

SQN 212, Bloco C, Apt. 106 -

ASA NORTE - Brasília-DF

CEP: $70.864-030$

Recebido em: 11/01/2012

Aprovado em: 11/01/2012

Movimento, Porto Alegre, v. 18, n. 01, p. 39-67, jan/mar de 2012. 
